\title{
Design and Experimental Study of the Rolling Enhanced Acoustic System for Gear Tooth Surface
}

\section{Yan Jiang ( $\nabla$ jiangyan@hpu.edu.cn )}

Henan Polytechnic University

Bo Zhao

Henan Polytechnic University

\section{Research Article}

Keywords: Double Nodes, Gear flank, Horn, Ultrasonic Surface Rolling, Residual Stress

Posted Date: November 2nd, 2021

DOI: https://doi.org/10.21203/rs.3.rs-960901/v1

License: (c) (1) This work is licensed under a Creative Commons Attribution 4.0 International License. Read Full License

Version of Record: A version of this preprint was published at The International Journal of Advanced Manufacturing Technology on January 21st, 2022. See the published version at https://doi.org/10.1007/s00170-022-08658-7. 


\title{
Design and Experimental Study of the Rolling Enhanced Acoustic System for Gear Tooth Surface
}

Yan Jiang, Bo Zhao*

\author{
School of Mechanical and Power Engineering, Henan Polytechnic University, Jiaozuo, 454150, China
}

\begin{abstract}
Parameters of gear flanks, such as roughness, hardness, and residual stress, impact their working performance. Therefore, it is essential to optimize these parameters for increasing gears' life. Thus, this study combined the meshing theory and the ultrasonic surface rolling technology, and presented an innovative design to realize ultrasonic burnishing. First, the dimensions of the ultrasonic burnishing device with two nodes integrated with a gear at the bottom were calculated using frequency equations by a numerical method. Second the correctness of the calculating results was verified by simulations and experiments. Third, the influence of the ratio between the width and diameter of the gear on the acoustic system was studied. Finally, experimental platform of the rolling enhanced acoustic system for gear tooth surface is built successfully. A series of experiments were conducted, and the results showed that the roughness decreased and the hardness and the residual stress improved. Therefore, this design provided a new theory and technology to machine complicated surfaces such as gear flanks.
\end{abstract}

Keywords: Double Nodes; Gear flank; Horn; Ultrasonic Surface Rolling; Residual Stress

\section{Introduction}

Driving characteristics require that the gear should bear wear resistance, high transmission efficiency, large bearing capacity, and so forth. The surface integrity of gears, including roughness, residual stress, and surface microstructure, determines the gears' performance. Tonshoff and Marzenel ${ }^{[1]}$ produced three groups of gears with different roughness and residual stress by changing the parameters of gear honing, and carried out pitting corrosion experiments using these three groups of gears. The results proved that the roughness and stress had a great influence on the fatigue life. Besides the quality of the initial gear surface, the running conditions in the initial cycle, that is, the running-in, also affected the fatigue life. Therefore, changing conditions of the initial surface affected the contact characteristics of gears.

During the initial gear meshing, the small bumps on the bear torque may lead to stress concentration at small bumps, thus causing micropits on the surface. Ariuraetal. ${ }^{[2]}$ proved that surface pits caused surface deterioration. The tooth surface needs to be smooth to avoid micropits so as to obtain better meshing characteristics. Soberg ${ }^{[3]}$ and Andersson ${ }^{[4]}$ examined the contact area of hobbing and shaving gears after the initial running-in; they showed that the roughness could be reduced after the initial running-in. The hobbing surface roughness was first larger, and then reduced significantly.

Thus, proper running-in can chang the surface morphology of the gear and improved the meshing characteristics. Furthermore, plastic deformation and wear caused surface micro-modification, especially in rollinglsliding contact ${ }^{[5]}$. Using a partial factorial design method, Oila and $\mathrm{Li}^{[6-7]}$ found pitting resistance was improved by reducing the surface roughness. Another study ${ }^{[8]}$ confirmed that the coarse gear surface was more prone to micro-pitting.

Bjorklund $^{[9]}$ found that the gear contact area ratio during honing and pure hobbling was higher than that during grinding gears. Some studies ${ }^{[10-11]}$ also showed that the ultra-finishing gear had lower surface roughness and higher gear contact efficiency compared with the grinding gear. In addition, other published studies demonstrated that the initial surface morphology had a significant influence on the fatigue contact characteristics of the gear surface ${ }^{[12]}$. Therefore, if the surface properties of the gear can be improved during the final machining, the fatigue life and wear resistance of the gear may be

\footnotetext{
* Corresponding author:

E-mail: zhaob@hpu.edu.cn
} 
positively affected.

A large number of studies were performed on ultrasonic hobbing, lapping, honing, slotting, and shaving ${ }^{[13-14]}$. However, they mainly focused on the processing method of material removal, but rarely on ultrasonic strengthening on the tooth surface. Simultaneously, ultrasonic rolling technology can improve the surface residual stress ${ }^{[15]}$ and hardness ${ }^{[16]}$, reduce the surface roughness and refine the grain ${ }^{[17-19]}$. Despite its many advantages, studies on ultrasonic rolling ${ }^{[20-21]}$ could not be directly applied to the strengthening on the gear surface. At the same time, previous studies showed ${ }^{[22-27]}$ that the initial running-in of the gear, and appropriate load and speed improved the surface integrity and affected the contact performance of the gear. Considering the excellent characteristics of ultrasonic rolling and the positive influence of initial running-in on gear surface performance, a set of rolling enhanced acoustic system (REAS) for the gear tooth surface was designed in this study.

\section{Strengthening mechanism of the gear tooth surface by ultrasonic rolling}

The schematic diagram of the rolling enhanced acoustic system for the gear tooth surface is shown in Figure 1. The working principle is as follows. First, the hardness between the tool gear(TG) and the workpiece gear(WG) is different, and the hardness of TG is about 30HRC higher than that of WG. Second, ultrasonic vibration is applied on the TG. Specifically, the TG is installed on the longitudinal vibration horn, whose back end is connected with a high-power transducer. The design frequency is set as $20 \mathrm{kHz}$ and a large-diameter chip design is chosen to manufacture the transducer. The TG can vibrate repeatedly along the axial direction under the drive of the transformer. The WG is mounted on dampers, which provides damping torques to the TG so that the pressure can be generated on tooth surfaces. The ultrasonic horn system(UHS) with gears is installed on the spindle, and the spindle has a cavity to accommodate UHS. The servo synchronous motor is installed on the back end of the spindle to provide power for UHS. The TG and WG are rolled and meshed with each other, so that the ultrasonic rolling enhancement can be completed.

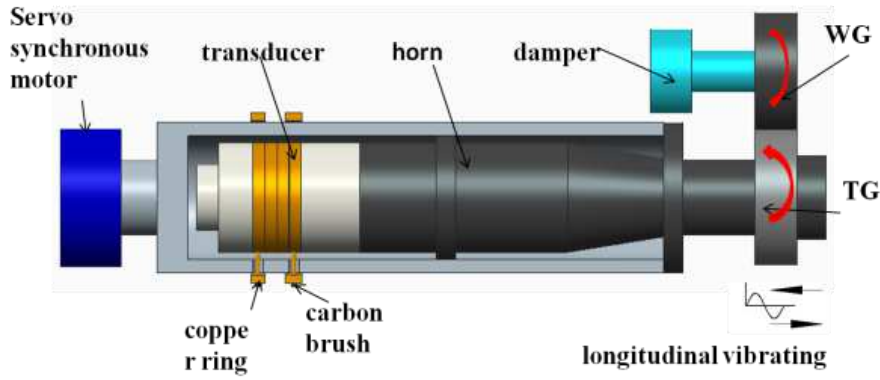

Figure 1. Schematic diagram of ultrasonic-enhanced tooth surface acoustic system

\section{Theoretical calculation of UHS}

\subsection{The theoretical calculation}

The key components of UHS are a transducer and a double-node horn. The transducers sold by merchants cannot meet the requirements of this system because of space, size, power, and other reasons. Therefore, the system in this study was a self-developed transducer. The conventional horn $(\lambda / 4, \lambda / 2,3 \lambda / 4)$ cannot meet the requirements because the normal force on the tooth surface of the ultrasonic meshing roller is applied to the horn. The horn with two nodes were selected to increase the stiffness of the system, and the horn was designed and calculated with one wavelength. The theory in the transducer field is developed, there the calculation was ignored in this study.

1- $\lambda$ Multi-segment double-node horn (DNMS)is complex, as shown in Figure 2a. According to the processing 
conditions, the horn must have two nodes, and one node should be located in the cylindrical section. To achieve this goal, first, the segment estimation method(SEM) was adopted to simplify the horn. The simplified horn is shown in Figure $2 b$.

Therefore, the following method was used for the SEM. Part I was the cylinder, and part II was the large cone with a small cylinder, which required the largest displacement (i.e., the force was 0) at the joint. The two parts were designed according to half wavelength. According to the propagation formula in the cylindrical rod, it was seen that: $c=\sqrt{E / \rho}$; $\lambda=c / f$; The horn was designed with $40 \mathrm{Cr}$,and the frequency was $20 \mathrm{kHz}, E=2.11 \times 10^{11} \mathrm{~Pa} ; \rho=7850 \mathrm{~kg} / \mathrm{m}^{3} ; \mathrm{C}=5170 \mathrm{~m} / \mathrm{s}$; $1 / 2 \lambda$ is $L_{1}=\frac{1}{2} \times \frac{5170 \times 10^{3}}{20 \times 10^{\wedge} 3}=130 \mathrm{~mm}$.

The resonance frequency equation of $1 / 2 \lambda$ cylinder with the conical horn was as follows:

$$
\tan \left(k L_{3}\right)=\frac{N a}{k}-\tan \left(k L_{2}+a_{2}\right)
$$

where $a_{2}=\arctan \left(\frac{a}{k}\right) ; N=\frac{D_{1}}{D_{2}}$; The input diameter of the transducer was $50 \mathrm{~mm}$. Considering the wave transmission characteristics, the diameter of the horn $D_{1}=52, D_{2}=36$. If $1 / 2 \lambda$ design calculation was used, then $L_{3}=60$ was calculated using Equation (1).

After the simplified size of the horn was estimated, the analytical method was used for accurate calculation. Neglecting the effects of shear deformation and moment of inertia, the displacement and strain equations of I, III, IV, and V sections in Figure 2 were as follows:

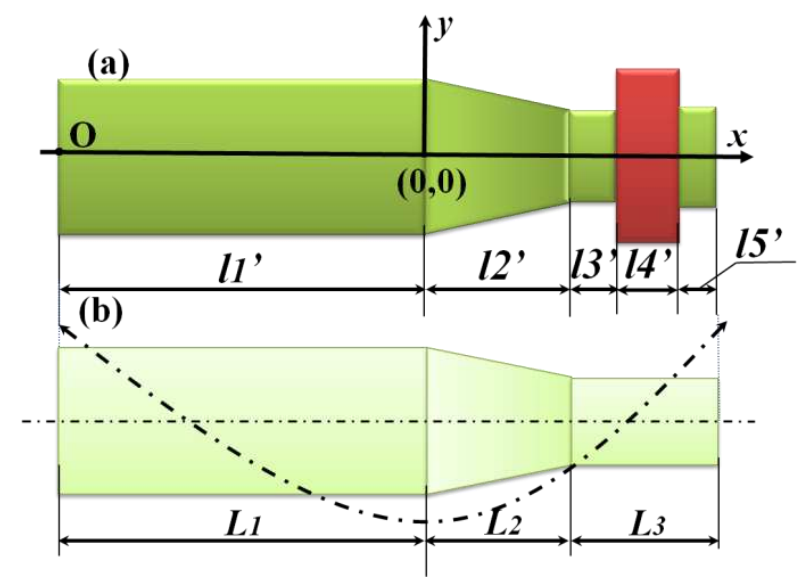

Figure 2. (a) Multi-segment horn; (b) simplified horn.

$$
\left\{\begin{array}{l}
\varepsilon_{i}=A_{i} \cos (k x)+B_{i} \sin (k x) ; i=1 ; 3 ; 4 ; 5 \\
\varepsilon_{i}^{\prime}=-A_{i} k \sin (k x)+B_{i} k \cos (k x)
\end{array}\right.
$$

According to the theory of longitudinal vibration, the displacement and strain equations of the conical rod (Section II) were obtained as follows: 


$$
\left\{\begin{array}{l}
\varepsilon_{2}=\frac{1}{x-\frac{1}{a}}\left(A_{2} \cos \left(k_{2} x\right)+B_{2} \sin \left(k_{2} x\right)\right) \\
\varepsilon_{2}=\frac{\partial \varepsilon}{\partial x}=\frac{1}{x-\frac{1}{a}}\left(-A_{2} k \sin \left(k_{2} x\right)+B_{2} k_{2} \cos \left(k_{2} x\right)\right) \\
-\frac{1}{\left(x-\frac{1}{a}\right)^{2}} \times\left(A_{2} \cos \left(k_{2} x\right)+B_{2} \sin \left(k_{2} x\right)\right)
\end{array}\right.
$$

where $a=D_{1}-\mathrm{D}_{2} / D_{1} l_{2}, k=\omega / c_{1}$ is the number of longitudinal wave, and $D_{1}$ and $D_{2}$ are the major and minor diameters of the cone, respectively. $A_{1}, B_{1}, A_{2}, B_{2}, A_{3}, B_{3}, A_{4}, B_{4}, A_{5}, B_{5}$ is the undetermined coefficient related to boundary and connection conditions. To satisfy the free boundary condition, the two ends of the multi-section horn were free:

$$
\left\{\begin{array}{l}
E \cdot\left(\varepsilon_{1}^{\prime}\right)_{x=l_{1}}=0 \\
E_{5} \cdot\left(\varepsilon_{5}^{\prime}\right)_{x=l_{2}+l_{3}+l_{4}+l_{5}}=0
\end{array}\right.
$$

If the displacement and force were continuous at the contact surface, the following conditions should be satisfied:

$$
\left\{\begin{array}{l}
\left(\varepsilon_{1}\right)_{x=0}=\left(\varepsilon_{2}\right)_{x=0} \\
E_{1} \cdot\left(\varepsilon_{1}^{\prime}\right)_{x=0}=E_{2} \cdot\left(\varepsilon_{2}\right)_{x=0} \\
\left(\varepsilon_{2}\right)_{x=l_{2}}=\left(\varepsilon_{3}\right)_{x=l_{2}} \\
E_{2} \cdot\left(\varepsilon_{2}\right)_{x=l_{2}}=E_{3} \cdot\left(\varepsilon_{3}\right)_{x=l_{2}} \\
\left(\varepsilon_{3}\right)_{x=l_{2}+l_{3}}=\left(\varepsilon_{4}\right)_{x=l_{2}+l_{3}} \\
E_{3} \cdot\left(\varepsilon_{3}^{\prime}\right)_{x=l_{2}+l_{3}}=E_{4} \cdot\left(\varepsilon_{4}^{\prime}\right)_{x=l_{2}+l_{3}} \\
\left(\varepsilon_{4}\right)_{x=l_{2}+l_{3}+l_{4}}=\left(\varepsilon_{5}\right)_{x=l_{2}+l_{3}+l_{4}} \\
E_{4} \cdot\left(\varepsilon_{4}^{\prime}\right)_{x=l_{2}+l_{3}+l_{4}}=E_{5} \cdot\left(\varepsilon_{5}\right)_{x=l_{2}+l_{3}+l_{4}}
\end{array}\right.
$$

By introducing displacement $\varepsilon_{i}$ and strain $\varepsilon_{i}^{\prime}$ into the aforementioned boundary conditions, Equation (6) was obtained.

$$
\left(\begin{array}{cccccccccc}
c_{11} & c_{12} & 0 & 0 & 0 & 0 & 0 & 0 & 0 & 0 \\
c_{21} & c_{22} & c_{23} & c_{24} & 0 & 0 & 0 & 0 & 0 & 0 \\
c_{31} & c_{32} & c_{33} & c_{34} & 0 & 0 & 0 & 0 & 0 & 0 \\
0 & 0 & c_{43} & c_{44} & c_{45} & c_{46} & 0 & 0 & 0 & 0 \\
0 & 0 & c_{53} & c_{54} & c_{55} & c_{56} & 0 & 0 & 0 & 0 \\
0 & 0 & 0 & 0 & c_{65} & c_{66} & c_{67} & c_{68} & 0 & 0 \\
0 & 0 & 0 & 0 & c_{75} & c_{76} & c_{77} & c_{78} & 0 & 0 \\
0 & 0 & 0 & 0 & 0 & 0 & c_{87} & c_{88} & c_{89} & c_{810} \\
0 & 0 & 0 & 0 & 0 & 0 & c_{97} & c_{98} & c_{99} & c_{910} \\
0 & 0 & 0 & 0 & 0 & 0 & 0 & 0 & c_{1009} & c_{1010}
\end{array}\right)\left(\begin{array}{c}
A_{1} \\
B_{1} \\
A_{2} \\
B_{2} \\
A_{3} \\
B_{3} \\
A_{4} \\
B_{4} \\
A_{5} \\
B_{5}
\end{array}\right)=0
$$

Equation (6) is a system of homogeneous equations of order 10 with $l_{1}, l_{2}, l_{3}, l_{4}, l_{5}$ and frequency as parameters and $A_{1}, B_{1}, A_{2}, B_{2}, A_{3}, B_{3}, A_{4}, B_{4}, A_{5}, B_{5}$ as unknowns.

Where: is $c_{j k}(j k=1,2, \ldots, 10)$ the coefficient in Equations (4)-(5). In order for homogeneous linear equation group have nonzero solutions, the determinant of the matrix of coefficients should be zero. This leads to the following frequency equation: 


$$
\mathrm{V}=\left|\begin{array}{cccccccccc}
c_{11} & c_{12} & 0 & 0 & 0 & 0 & 0 & 0 & 0 & 0 \\
c_{21} & c_{22} & c_{23} & c_{24} & 0 & 0 & 0 & 0 & 0 & 0 \\
c_{31} & c_{32} & c_{33} & c_{34} & 0 & 0 & 0 & 0 & 0 & 0 \\
0 & 0 & c_{43} & c_{44} & c_{45} & c_{46} & 0 & 0 & 0 & 0 \\
0 & 0 & c_{53} & c_{54} & c_{55} & c_{56} & 0 & 0 & 0 & 0 \\
0 & 0 & 0 & 0 & c_{65} & c_{66} & c_{67} & c_{68} & 0 & 0 \\
0 & 0 & 0 & 0 & c_{75} & c_{76} & c_{77} & c_{78} & 0 & 0 \\
0 & 0 & 0 & 0 & 0 & 0 & c_{87} & c_{88} & c_{89} & c_{810} \\
0 & 0 & 0 & 0 & 0 & 0 & c_{97} & c_{98} & c_{99} & c_{910} \\
0 & 0 & 0 & 0 & 0 & 0 & 0 & 0 & c_{1009} & c_{1010}
\end{array}\right|=0
$$

For the given resonant frequency and sizes of the horn, the geometrical sizes of the horn can be calculated.

Excitation of a simple harmonic oscillation displacement at the input end surface $\mathrm{O}$ is

$$
\left.\varepsilon\right|_{x=-l_{1}}=\varepsilon e^{j w t}=\left(A_{1} \cos k_{1} l_{1}+B_{1} \sin k_{1} l_{1}\right) e^{j w t}
$$

Combining equation (8) with equations (4) to (5) yields:

$$
\left(\begin{array}{cccccccccc}
c_{11} & c_{12} & 0 & 0 & 0 & 0 & 0 & 0 & 0 & 0 \\
c_{21} & c_{22} & c_{23} & c_{24} & 0 & 0 & 0 & 0 & 0 & 0 \\
c_{31} & c_{32} & c_{33} & c_{34} & 0 & 0 & 0 & 0 & 0 & 0 \\
0 & 0 & c_{43} & c_{44} & c_{45} & c_{46} & 0 & 0 & 0 & 0 \\
0 & 0 & c_{53} & c_{54} & c_{55} & c_{56} & 0 & 0 & 0 & 0 \\
0 & 0 & 0 & 0 & c_{65} & c_{66} & c_{67} & c_{68} & 0 & 0 \\
0 & 0 & 0 & 0 & c_{75} & c_{76} & c_{77} & c_{78} & 0 & 0 \\
0 & 0 & 0 & 0 & 0 & 0 & c_{87} & c_{88} & c_{89} & c_{810} \\
0 & 0 & 0 & 0 & 0 & 0 & c_{97} & c_{98} & c_{99} & c_{910} \\
0 & 0 & 0 & 0 & 0 & 0 & 0 & 0 & c_{1009} & c_{1010}
\end{array}\right)\left(\begin{array}{c}
A_{1} \\
B_{1} \\
A_{2} \\
B_{2} \\
A_{3} \\
B_{3} \\
A_{4} \\
B_{4} \\
A_{5} \\
B_{5}
\end{array}\right)=\left(\begin{array}{c}
\varepsilon \\
0 \\
0 \\
0 \\
0 \\
0 \\
0 \\
0 \\
0
\end{array}\right)
$$

Input the given geometrical sizes and the resonant frequency from equation (7) to solve for $A_{1}, B_{1}, A_{3}, B_{3}, A_{5}, B_{5}$ by expression of $\varepsilon$ at $x=l_{1}$ according to equation (9), the displacement amplification factor can be calculated using:

$$
M=\left|\frac{\left.\varepsilon\right|_{x=l_{5}}}{\left.\varepsilon\right|_{x=l_{1}}}\right|=\left|\frac{\left.\varepsilon\right|_{x=l_{5}}}{\left.\varepsilon\right|_{x=l_{1}}}\right|=\left|\frac{A_{5} \cos k_{5} l_{5}+B_{5} \sin k_{5} l_{5}}{A_{1} \cos k_{1} l_{1}+B_{1} \sin k_{1} l_{1}}\right|
$$

The coefficient $A_{1}, B_{1}, A_{3}, B_{3}$ is known; The displacement equations of segment 1 and segment 3 can be known, When $x_{0}^{1}=0 ; \quad A_{1} \cos k_{1} x_{0}^{1}+B_{1} \sin k_{1} x_{0}^{1}=0, \quad x_{0}^{2}=0, A_{3} \cos k_{3} x_{0}^{2}+B_{3} \sin k_{3} x_{0}^{2}=0$; then $x_{0}^{1}, x_{0}^{2}$ are the double nodes of the horn.

\subsection{Theoretical design}

The length value of segmented estimation is $l_{1}=130, l_{2}=60, l_{3}=60$.If $L_{3}$ was evenly divided into three segments of $i_{3}^{\prime}, l_{4}^{\prime}$, and $l_{5}^{\prime}$, and each segment was $20, l_{3}^{\prime}=l_{4}^{\prime}=i_{5}^{\prime}=20$. When the frequency was $20 \mathrm{kHz}$, the values of $l_{1}^{\prime}$ and $l_{3}^{\prime}$ were adjusted so that Equation (7) was applicable. A computer program was written. In put the given sizes and set a loop to solve the resonant length according to equation (7), then $l_{1}^{\prime}=120, l_{3}^{\prime}=31$ were obtained ( As shown in Figure 3). The final dimensions of the horn were $l_{1}^{\prime}=120 ; l_{2}^{\prime}=50 ; l_{3}^{\prime}=31 ; l_{4}^{\prime}=20 ; l_{5}^{\prime}=9$. 


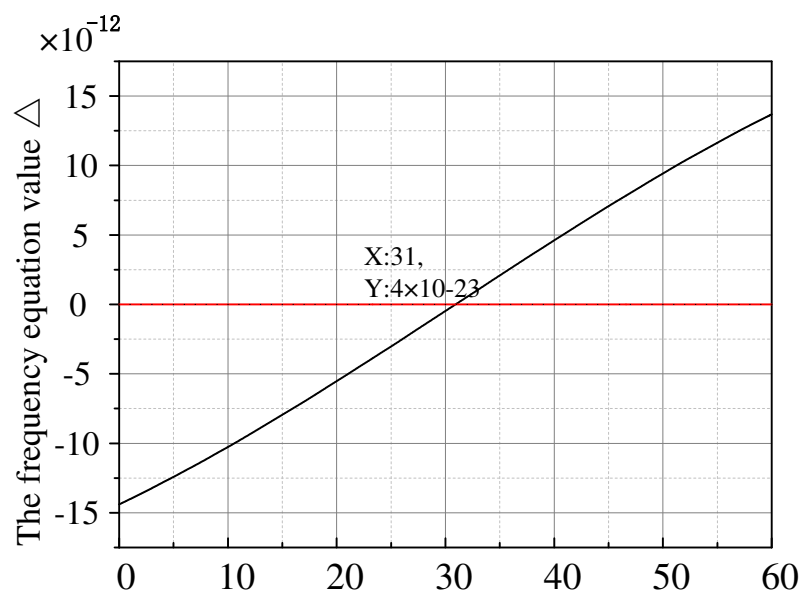

Figure 3. The solution curve for $l_{3}^{\prime}$

If the length and frequency were included in Equation (7), $A_{1}, B_{1}, A_{2}, B_{2}, A_{3}, B_{3}, A_{4}, B_{4}, A_{5}, B_{5}$ were obtained. another program was written to get the amplification factor: $M=1.5$. The third program was written to find double nodes, and the specific results are shown in Figure 4 and Figure 5. If the origin of coordinates is the big end of the whole horn, then coordinates of two nodes are:

$(56,0),(184,0)$.

\section{Simulation result and analysis of UHS}

In real applications, the question is how the replacement of the TG affects the performance of the UHS. The theoretical calculation is too complicated and not intuitive. In this section, the modal analysis and harmonic response module were used to study the characteristics of the UHS. The influence of the TG (diameter and thickness) on frequency and amplitude for UHS was studied. The theoretical calculations in Section 2 are also verified.

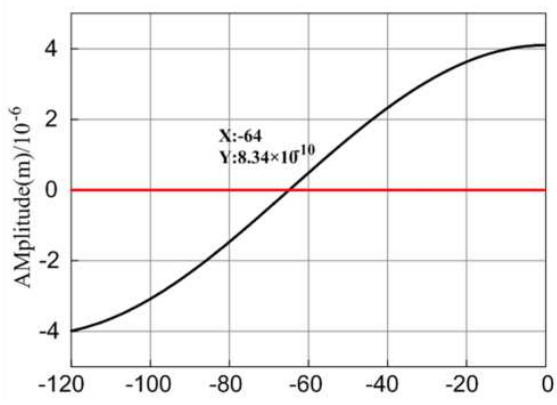

Figure 4. Node near the big end

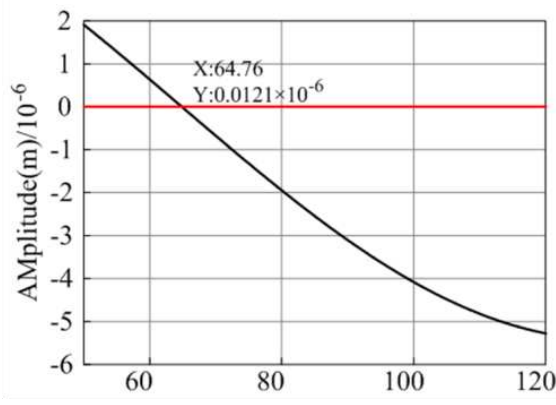

Figure 5. Node near the small end

\subsection{Influence of gear diameter on the frequency/node}

span

The length dimension $l_{1}^{\prime}=120 ; l_{2}^{\prime}=50 ; l_{3}^{\prime}=31 ; l_{4}^{\prime}=20 ; l_{5}^{\prime}=9$ remained unchanged, while the gear diameter was changed from $40 \mathrm{~mm}$ to $70 \mathrm{~mm}$ (modulus was $2, \mathrm{z}=20 / 25 / 30 / 35 / 40$ ). The mode of longitudinal vibration (near $20 \mathrm{kHz}$ ) was found in ANSYS. The values in Table 1 were obtained under the longitudinal mode. The following conclusions can be drawn: As the diameter (mass) increased, the frequency of UHS decreased. The node position of the horn moved to the end 
of the gear with the continuous increase in the gear mass, and the span between the two node positions also increased with the increase in the gear mass. When the TG was replaced, the mass of the whole gear increased as the number of teeth increased. To maintain the balance, the system needed to increase the span, and the double nodes moved toward the direction of mass increase.

\subsection{Influence of gear thickness on the frequency/node span}

The size of the horn, $l_{1}^{\prime}=120 ; l_{2}^{\prime}=50 ; l_{3}^{\prime}=31 ; l_{4}^{\prime}=20 ; l_{5}^{\prime}=9$, remained unchanged, and the diameter $D_{3}$ was $60 \mathrm{~mm}(m=2$, $z=30$ ). The thickness of the gear ranged from $5 \mathrm{~mm}$ to $25 \mathrm{~mm}$. The longitudinal vibration mode (near $20 \mathrm{kHz}$ ) was found in ANSYS, and the values in Table 2 could be obtained under the longitudinal vibration mode. $f_{a} 、 N_{a} 、 S_{a}$ and $f_{e} 、 N_{e}$ 、 $S_{e}$ are the frequencies、nodes and span(the distance between two nodes) arrived at using the analytical method described above and using the finite element method respectively. The errors between $f_{a}$ and $f_{e}, N_{a}$ (node coordinate) and $N_{e}$ 、 $S_{a}$ and $S_{e}$ were $\mathrm{V}_{1}=\left|\left(f_{a}-f_{e}\right) / f_{a}\right|, \mathrm{V}_{2}=\left|\left(N_{a}-N_{e}\right) / N_{a}\right|$, and $\mathrm{V}_{3}=\left|\left(S_{a}-S_{e}\right) / S_{a}\right|$.

Table 1. Influence on node position and frequency

\begin{tabular}{cccccccc}
\hline Diameter $(\mathrm{mm})$ & mass $(\mathrm{kg})$ & Frequency $(\mathrm{kHz})$ & $\mathrm{V}_{1} \%$ & Double Node & $\mathrm{V}_{2} \%$ & Span $(\mathrm{mm})$ & $\mathrm{V}_{3} \%$ \\
\hline 40 & 0.101 & 22.336 & 11 & $56 \backslash 170$ & $-1.7 \backslash 7.6$ & 114 & 10 \\
50 & 0.22 & 21.512 & 7 & $59 \backslash 173$ & $3.5 \backslash 5.9$ & 114 & 10 \\
60 & 0.35 & 20.268 & 1 & $64 \backslash 176$ & $11.2 \backslash 4.3$ & 112 & 12.5 \\
70 & 0.52 & 19.025 & 4 & $68 \backslash 178$ & 19.213 .2 & 110 & 14 \\
80 & 0.65 & 18.012 & 9 & $70 \backslash 184$ & $22.8 \backslash 0$ & 114 & 10 \\
\hline
\end{tabular}

The error between the two-node simulation value and the theoretical value is shown in Table 1. As the diameter of node 1 increases, the position of node 1 gradually gets closer to the small end, so the error becomes larger and larger, while the error of node 2 gradually decreases with the increase of diameter. The span error is stable and the span of simulation calculation is smaller than that of theoretical calculation. This is because only the influence of length is considered in the theoretical calculation, and the influence of gear diameter is not considered.

As shown in Table 2, the diameter was unchanged, but its mass continued to increase with the increase in the thickness; also, the frequency tended to decrease, but the change was small. When the thickness was $5 \mathrm{~mm}$, the frequency changed the most because the ratio of thickness to diameter was 0.083 ; also, the vibration of the gear was thin-plate vibration, which was a little bit different from the longitudinal mode. The vibration frequencies of other thicknesses varied very little. When the gear thickness was changed, the frequency and node position of the UHS changed little. Therefore, the change in thickness in a small range had little effect on the frequency and node position of the UHS.

Figure 6 is the modal analysis of a gear with a diameter of $50160170 \mathrm{~mm}$ (module of 2 and teeth of 25130135, respectively). First, the vibration of the horn was weak in two places, namely, two nodes. The resonant frequency decreased with the increase in gear diameter. Compared with $20 \mathrm{kHz}$, the error of the diameter-50160170 system was $7.62 \%, 1.34 \%$, and $4.875 \%$. Further, the correctness of the horn dimension calculated in the first section was verified. 


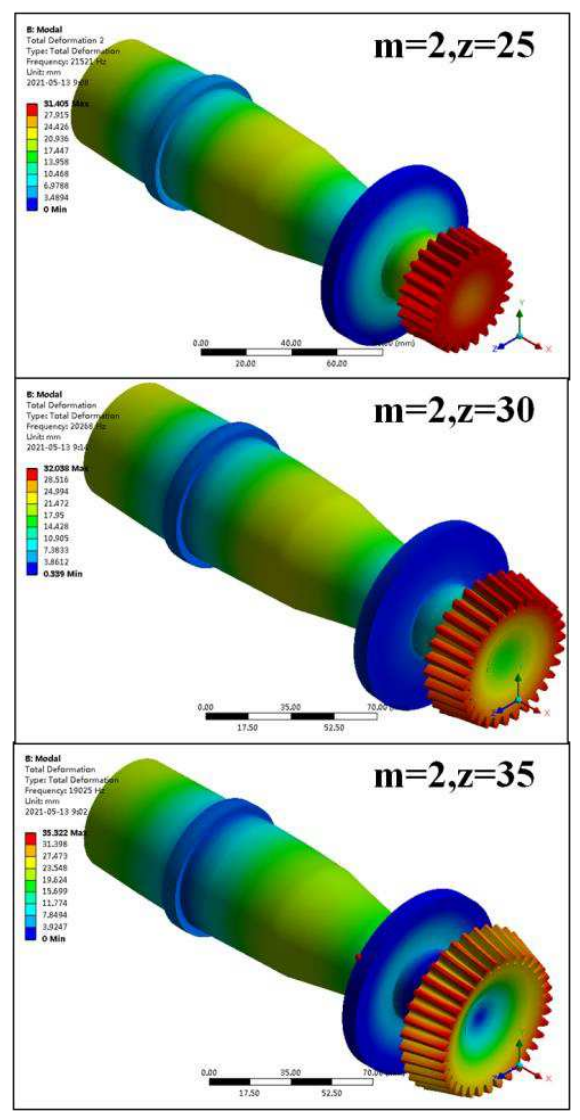

Figure 6. Diameter50\60170 mm modal diagram.

\subsection{Influence of gear diameter on the amplitude/node span}

The horn was modeled according to the dimension calculated in Section 1.The thickness of the gear was 20mm, and the diameter was $40150160 \mathrm{~mm}$ (the number of teeth was 20125130) for modeling. After the modeling was in Creo, the model was imported into the harmonic response module in ANSYS. Then, the effect of diameter variation on amplitude was studied.

Table 2. Influence of gear thickness on node and frequency

\begin{tabular}{ccccccc}
\hline Thickness (mm) & Mass(kg) & Frequency $(\mathrm{Hz})$ & Double Node & $\mathrm{V}_{2} \%$ & Span $(\mathrm{mm})$ & $\mathrm{V}_{3} \%$ \\
\hline 5 & 0.088 & 23.301 & $64 \backslash 179$ & $12 \backslash 2.7$ & 100 & $21 \%$ \\
10 & 0.17 & 20.842 & $64 \backslash 174$ & $12 \backslash 5.4$ & 109 & $14 \%$ \\
15 & 0.26 & 20.676 & $64 \backslash 179$ & $12 \backslash 2.7$ & 110 & $14 \%$ \\
20 & 0.35 & 19.804 & $64 \backslash 178$ & $12 \backslash 3.2$ & 114 & $10 \%$ \\
25 & 0.44 & 19 & $64 \backslash 181$ & $12 \backslash 1.6$ & 117 & $8 \%$ \\
\hline
\end{tabular}

In ANSYS, the displacement excitation applied was the same, and the magnitude was $4 \mu \mathrm{m}$.Two flanges were set at the nodes. The constraint position was the same, with two flanges. The ultrasonic horn with different gears was used in the harmonic response. The amplitudes of the same system at different frequencies are shown in Figure 7(a-d). In a harmonic response, under the longitudinal vibration condition, the relationship between frequency and amplitude was recorded for the same system (Figure $7(\mathrm{a}-\mathrm{c})$. When the frequency of longitudinal vibration was found at first, the amplitude was relatively large. The amplitude gradually decreased as the frequency increased. For the same system, the span of the system decreased 
with the decrease in vibration, but not much. Under longitudinal vibration, the positions of the two nodes had something in common: the position of the node close to the gear basically remained unchanged with the increase in vibration frequency, while the position of the node close to the transducer changed the span dimension with the strength of the amplitude.

When the vibration was strong, the span was large, and vice versa. As shown in Figure 7, the amplitude of the horn without gear (HWG) was the largest; it was $0.019 \mathrm{~mm}$. The HWG was compared with the system with gear(SWG):The node position of the HWG was closer to the end of the transducer than that of the SWG. Meanwhile, a high amplitude existed between the two nodes; this amplitude of the HWG was smaller than that of the SWG. This was because, with the addition of the gear, the mass of the whole system became larger, reducing the amplification effect. Consequently, the system wasted some vibration energy, thus weakening the amplification effect of the horn.

As shown in Figure 7(a-c), the three systems followed the same law: As the frequency increased, the amplitude decreased. The comparison among the systems of different gears showed that the same law in Sections 3.1 - 3.2 was used. That is: When different gears were installed in the UHS, the frequency and amplitude decreased with the increase in the diameter of the gear.

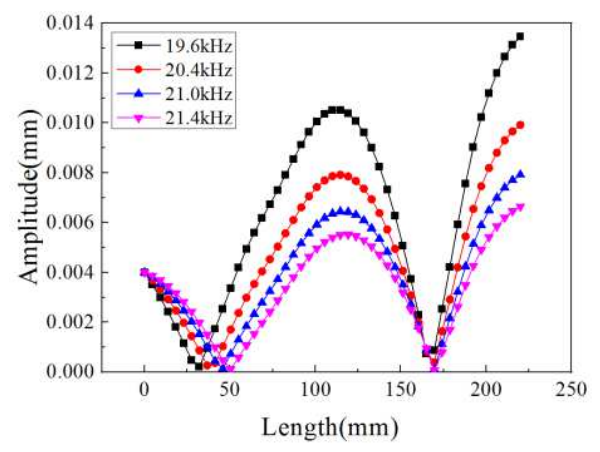

(a) Dia.60-system

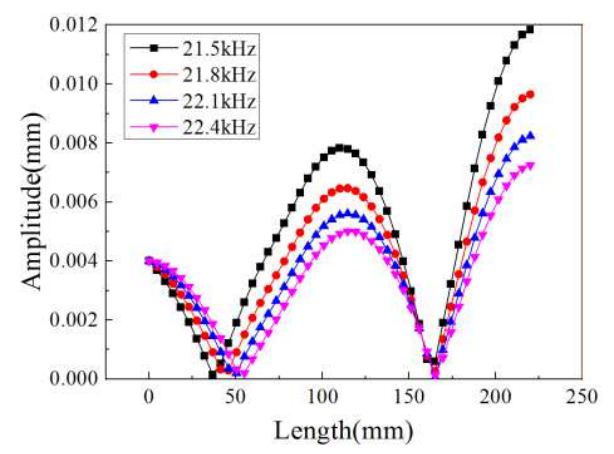

(c) Dia.40-system

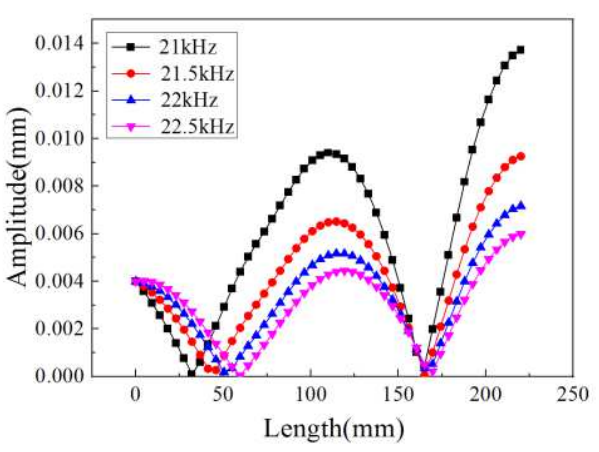

(b) Dia.50-system

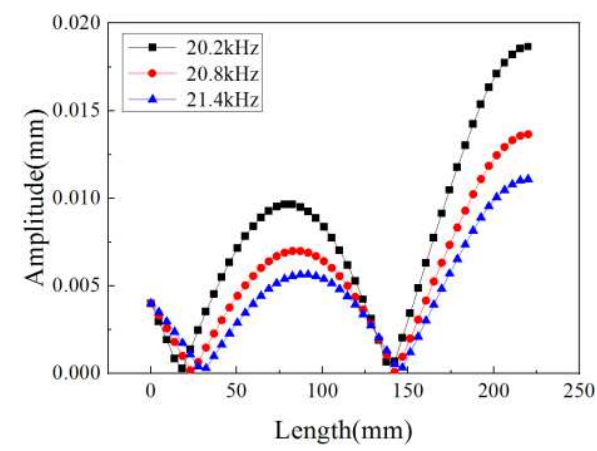

(d) Single horn

Figure 7. Frequency-amplitude diagram

Therefore, the node position and resonant frequency of the ultrasonic system were different with different gears installed.

The resonant amplitudes of different gears at the same frequency were studied ( 4 cases: diameter $40 / 50 / 60 /$ none). If the excitation displacement was the same, the UHS with different gears (diameter 40/50/60/none) was used for comparison at $21 \mathrm{kHz}$.

Figure 8 shows that the amplitude of the system with no gear was the largest. It was also clear that after the installation of gears, the node position of the UHS moved toward the gear, and the span remained basically the same (this rule was also seen in Sections 2.1.1 and 2.1.2).

At the same frequency, the amplitude of the UHS (diameter40/50/60) decreased as the diameter increased. The 
40-mm-diameter gear had the largest amplitude because $21 \mathrm{kHz}$ was close to the resonance point of the UHS with the 40-mm-diameter gear and away from the resonant point of the UHS with the 50/60-mm-diameter gear. It was meaningless to compare the amplitudes of different systems at the same frequency. However, the positions of double nodes of different systems were approximately the same at the same frequency, which provided a design basis for later manufacturing.

As shown in Sections3.1 - 3.3, the increase in gear mass did not necessarily lead to the change in system frequency, which depended on the direction of mass increase. The increase in mass caused by diameter had a great influence on system frequency. Meanwhile, it was concluded that the increase in diameter had a major influence on nodes and frequency. The analysis in the aforementioned section indicated that the UHS could still resonate and the node position basically remained within a small range when changing different tool gears (with a small range of changes in the number of teeth), which provided a favorable basis for manufacturing.

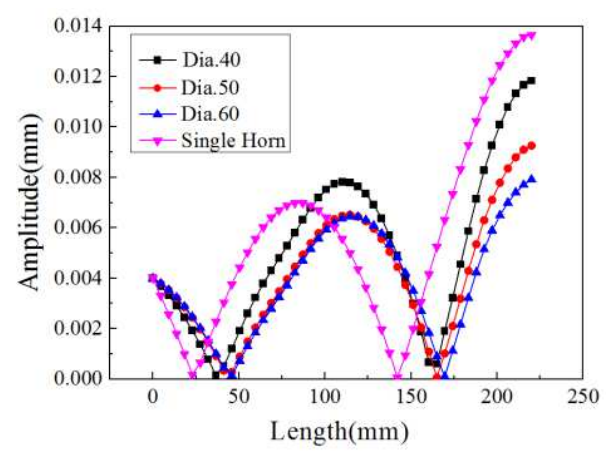

Figure 8. Amplitude comparison of different systems $(21 \mathrm{kHz})$.

\section{Experiment on the vibration characteristics of UHS}

The vibration effect of the horn was different with different materials; 40Cr and SKD11 were used to make the horn. The vibration performance of the two materials was tested on self-made $20-\mathrm{kHz}$ transducers.

The parameters, such as natural frequency, dynamic resistance, and quality factor, were measured using a PV70A damping analyzer (Bandera Electronics co., Ltd). After the assembly of the horn (SKD11) and the self-made transducer, the resonant frequency was $20,910 \mathrm{~Hz}$, the anti-resonant frequency was $22,419 \mathrm{~Hz}$, the impedance was $11 \mathrm{ohm}$, and the quality factor was 2119. After the assembly of the horn $(40 \mathrm{Cr})$ and the transducer, the resonant frequency was $20,198 \mathrm{~Hz}$, the anti-resonant frequency was $20,215 \mathrm{~Hz}$, the impedance was $24 \mathrm{ohm}$, and the quality factor was 1039 .

As shown in Figure. 9, the admittance circle curves of the two materials were normal, and the dynamic resistance value was small. First, compared with the design frequency of $20 \mathrm{kHz}$, the error(SKD11 and $40 \mathrm{Cr}$ ) was $4.5 \%$ and $0.93 \%$,respectively, which verified the correctness of the theoretical calculation. Second, the vibration transmission efficiency of the SKD11 horn was better. The impedance was only $11 \mathrm{ohm}$, and the quality factor was $103 \%$ higher than that of the $40 \mathrm{Cr}$ material. This was mainly caused due to SKD11's excellent characteristics, such as high toughness, high hardness, and compact structure ${ }^{[28-29]}$. Therefore, the subsequent tests in this study adopted the horn made by SKD11.

As shown in Tables 1 and 2, two points had the smallest displacement, namely two nodes. However, flange thickness was required for design and manufacturing. The flange thickness was $8 \mathrm{~mm}$. The thickness centerline of Flange I was $67 \mathrm{~mm}$ from the large end (flange span 63-70 mm).The thickness centerline of Flange Ivas $180 \mathrm{~mm}$ from the large end (flange span 176-184mm). According to the FEA, gears with the diameter of 60/70/80 mm could be installed on the horn. The errors between $f_{m}$ are the measured frequencies. The errors between $f_{a}$ and $f_{m}$ was $\mathrm{V}_{4}=\left|\left(f_{a}-f_{m}\right) / f_{m}\right|$.The ultrasonic horn was assembled using a transducer, a horn, and a gear, as shown in Figure 10. The natural frequency, dynamic resistance, and quality factor of the horn were measured using a PV70A impedance analyzer. The influence of different gears on system frequency was examined with the impedance analyzer. The frequency of the system was reduced when the horn was added 
to the gear (Table 3), which was the same as the simulation results in Section 3. Although the frequency decreased, it still met the requirements. At the same current, the amplitude of the single horn was obviously larger than that of the horn with the gear. After installing the gear, energy was lost; therefore, the amplitude of the gear was generally smaller. When the diameter increased, the quality factor/frequency decreased, and the resistance increased. This suggested that the larger the gear, the weaker the vibration transmission effect. The experimental test frequency had a similar trend to simulation. With the increase in gear diameter, the frequency of the system gradually reduced, showing the effectiveness of finite element simulation.

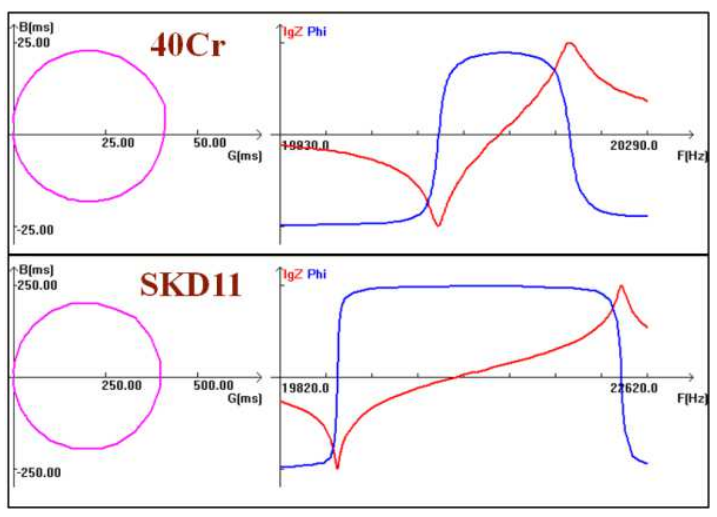

Figure 9 Impedance diagram of the horn.

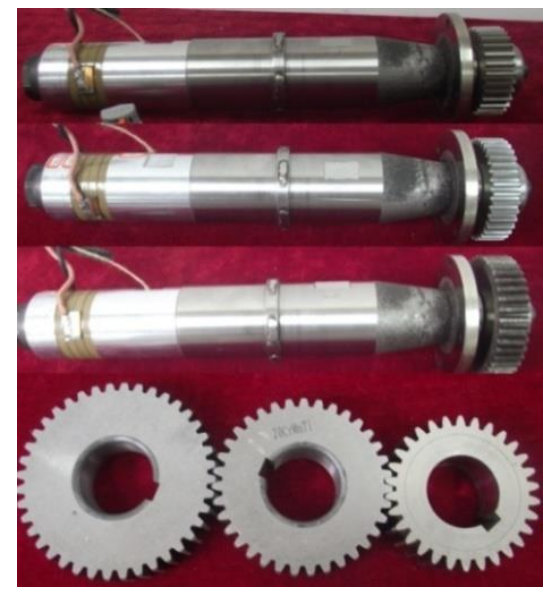

Figure 10. Ultrasonic horn system.

Table 3. Impedance measurement results

\begin{tabular}{cccccccc}
\hline $\begin{array}{c}\text { Diameter } \\
(\mathrm{mm})\end{array}$ & $\begin{array}{c}\text { Experimental Frequency } \\
(\mathrm{Hz})\end{array}$ & $\begin{array}{c}\mathrm{V}_{4} \\
(\%)\end{array}$ & $\begin{array}{c}\text { Dynamic resistance } \\
(\Omega)\end{array}$ & Quality factor & $\begin{array}{c}\text { Amplitude } \\
(\mu m)\end{array}$ & $\begin{array}{c}\text { Flange I } \\
\text { Amplitude }(\mu m)\end{array}$ & $\begin{array}{c}\text { Flange } \\
\text { Amplitude }(\mu m)\end{array}$ \\
\hline 60 & 20,186 & 0.93 & 49.58 & 693.1 & 4.1 & 0.00002 & 0.0002 \\
70 & 19,134 & 4.33 & 53.49 & 690.1 & 3.8 & 0.00001 & 0.0003 \\
80 & 18,877 & 5.61 & 72.22 & 598.1 & 3.6 & 0.00005 & 0.0002 \\
Single horn & 20,910 & 4.55 & 11 & 1819 & 5.7 & 0.00002 & 0.0003 \\
\hline
\end{tabular}

One-way excitation was applied to the system, and the longitudinal vibration was generated on the system. The vibration characteristics were measured using the LK-G10 (Keyence, Japan) laser displacement sensor. Figure 11 shows that the largest amplitude of SKD11 horn (without gear) was $5.3 \mu \mathrm{m}$, the minimum amplitude was $-4.8 \mu \mathrm{m}$, and the current was 0.8 A. A TG with a diameter of $60 \mathrm{~mm}$ was installed on the horn, and then the frequency of $2909 \mathrm{kHz}$ was applied. The maximum amplitude of the system was $4.3 \mu \mathrm{m}$, the minimum was $-4.1 \mu \mathrm{m}$, and the current was $0.8 \mathrm{~A}$.Thisindicated that the amplitude of the former was large, and the amplitude decreased with the installation of the gear. The amplitude was adjusted by adjusting the current. Little difference was observed in the system amplitude of different gears, indicating that the four gears could achieve good longitudinal vibration effects under the same horn.

\section{Experimental and discussion on REAS}

The ultrasonic rolling tooth surface was used on the self-developed experimental device (Figure.12). The permanent magnet motor was used to provide a torque for TG (parameters: rated power $4.8 \mathrm{~kW}$, rated speed $1000 \mathrm{R} / \mathrm{min}$, rated current 9.2 A), and the brake (rated current $3.5 \mathrm{~A}$, power $84 \mathrm{~W}$, rated torque $400 \mathrm{Nm}$ ) provided a damping torque for the WG. The TG was subjected to ultrasonic vibration along the axial direction, and a damping torque was observed on the WG. The TG 
made the WG rotate, and then the tooth surface was strengthened.

The TG material was $20 \mathrm{CrMnTi}$, the surface was carburized and quenched, and the hardness was 58-62HRC. The WG material was $12 \mathrm{Cr} 2 \mathrm{Ni} 4 \mathrm{~A}$; it was quenched and tempered, and the hardness was $26-30 \mathrm{HRC}$ (No special instructions are in this state). TG parameters were as follows: $m=2, z=30$. WG parameters were as follows: $m=2$, and the number of teeth 30 . The experimental parameters are shown in Table 4.
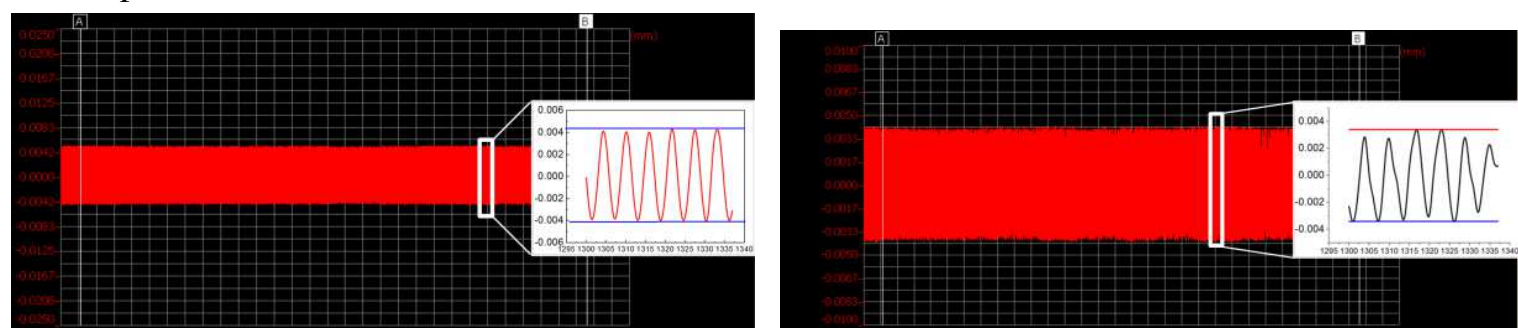

(a)Amplitude of the system(only horn) (b)Amplitude of the system(with a gear whose diameter is 60mm)

Figure 11. Amplitude comparison of the system.

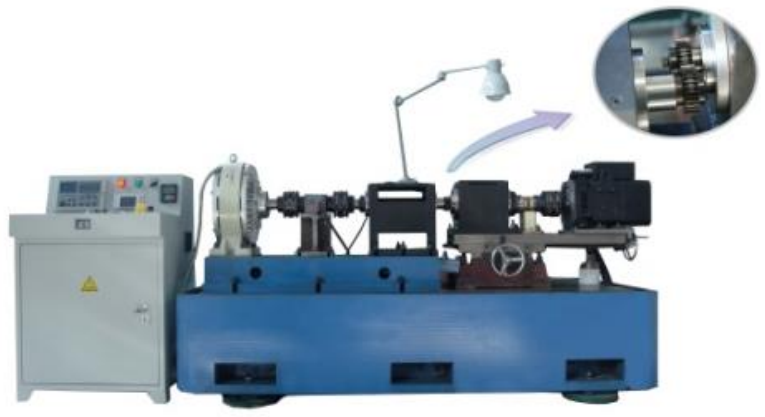

Figure 12. Self-developed experimental device

Table 4. Processing experimental parameters

\begin{tabular}{cccc}
\hline Speed (r/min) & Frequency $(\mathrm{kHz})$ & Amplitude $\mu m$ & Torque (Nm) \\
\hline 30 & 19.98 & 4.3 & $30-90$ \\
\hline
\end{tabular}

The following were described from two aspects: system characteristics and tooth surface properties after ultrasonic rolling.

\subsection{System excellent characteristics}

Tonshoff and Marzenell pointed out ${ }^{[30]}$ that honing achieved a larger axial and contour direction of compressive residual stress because honing applied a larger mechanical load at a lower temperature, and grinding produced larger grinding heat. The ultrasonic rolling process also had excellent characteristics of honing. The temperature of the ultrasonic rolling process was measured with an infrared thermometer FLIR-T540 (FLIR, USA). The maximum temperature in the rolling process was not more than $40^{\circ} \mathrm{C}$, as shown in Figure 13, which was very beneficial to the final processing of the tooth surface. 


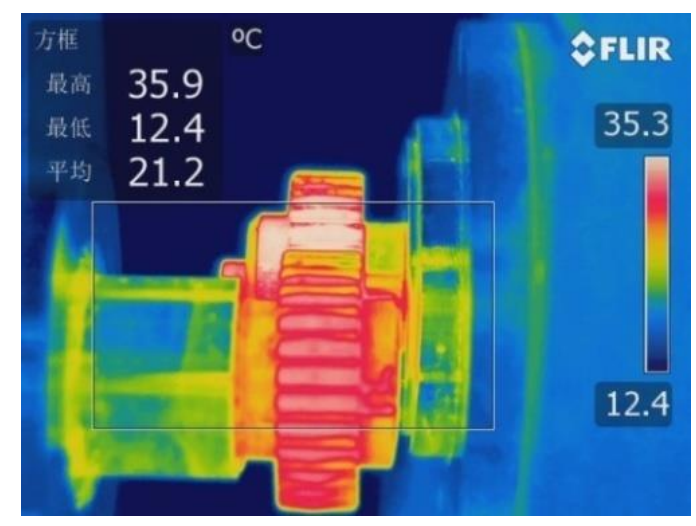

Figure 13. Temperature in process.

\subsection{The result after ultrasonic rolling}

After ultrasonic rolling, the gear teeth were divided into blocks using wire-electrode cutting to observe the state of the surface residual stress and surface topography. A digital Rockwell hardness tester (HRS-150) was used to measure the microhardness. The surface residual stress was measured by a PROTO-LXRD residual stress analyzer, with a Cr radiation target, a tube voltage of $30 \mathrm{kV}$ and current of $25 \mathrm{~mA}$. A German-made Scanning Electron Microscope (Merlin Compact) was used for morphological observation.

(1) Residual stress

When the damping torque is $80 \mathrm{Nm}$, the rolling time is $2-8$ hours and the residual stress on the tooth surface is shown in Figure. 14. It can be seen that the residual stress increases at first and then decreases with the accumulation of time. The maximum residual stress is $515.5 \mathrm{MPa}$ after 6 hours of rolling, which is 4.1 times higher than the initial residual stress -100 $\mathrm{MPa}$, then, with the increase of time accumulation, the rolling pressure decreased to $-366 \mathrm{MPa}$ in 8 hours. The results show that when rolling time is 6 hours, the grain refinement degree is the highest, and the amount of deformed martensite is the largest. After rolling, the amount of deformed martensite decreases, grain defects and martensite damage result in the reduction of residual stress.

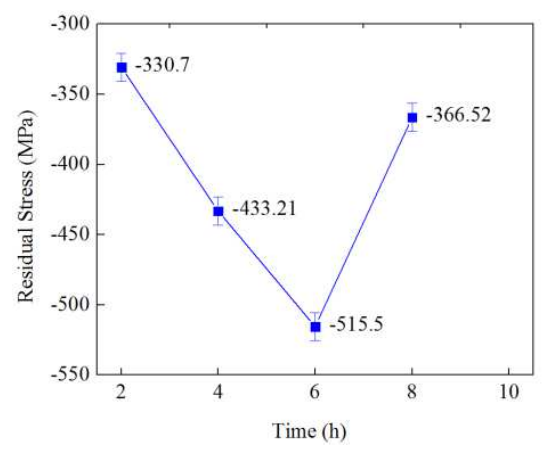

Figure 14. Effect of time on residual stress

(2) Hardness

In order to analyze the influence of time on the hardness of the tooth surface in the ultrasonic rolling method, the damping torque is selected as $30 \mathrm{Nm}$, and the gears of $12 \mathrm{Cr} 2 \mathrm{Ni} 4 \mathrm{~A}$ with and without tempered are tested separately. The hardness of the tooth surface is tested every 10 minutes. As can be seen from the Figure 15, the hardness increases monotonously during the initial rolling process and periodically with the increase of time. The material has a cycle softening and hardening. As the quenched and tempered steel (QTS) is relatively soft, its hardness range is larger than that of the unquenched and tempered steel (NTS), the initial hardness of NTS is higher, and the hardness change amplitude is smaller, 
however, it can be seen that the material is cyclic softening and hardening, and the hardness increases with time, which indicates that the increase of surface hardness takes time to accumulate. During the ultrasonic rolling process, some dislocations will cancel each other with the dipolar dislocations of the different symbols formed in the double sliding, or disappear by other ways, thus leading to softening, the lattice distortion in the softening zone restores and the sub-grains grow up, which leads to the decrease of hardness. The ultrasonic rolling method will lead to the increase of dislocation value again, and the grain refinement hardness will increase again, this results in cyclic softening and hardening.
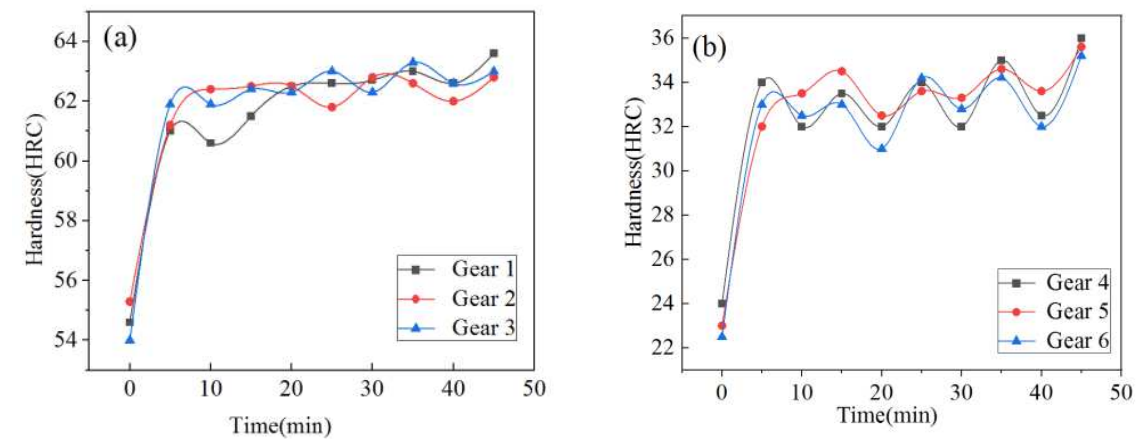

Figure 15. Time hardness diagram

\section{(3) Surface quality}

In order to study the influence of the damping torque on the surface topography, the area near the gear pitch circle was selected as the research object, and the surface topography under different torques was compared and studied. As shown in Figure 16, the untreated gear surface has obvious peaks and valleys along the axial direction (gear width direction), which are characterized by grinding marks. This kind of peak and valley contributes a lot to the local stress concentration, so it is not conducive to the fatigue performance of the gear. After processing, for the $30 \mathrm{Nm}$ sample, the mechanical grinding marks along the axial direction are reduced. This smooth surface is caused by the effect of ultrasonic rolling. Under ultrasonic rolling, the material with high peaks on the tooth surface flows to the valleys. For the $60 \mathrm{Nm}$ specimen, the distance between peaks and valleys is enlarged, and the peaks and valleys of the $80 \mathrm{Nm}$ specimens almost disappear. Larger plastic deformation occurs on the surface of the sample, the surface after treatment is more uniform, and the surface height difference is gradually reduced. It can be seen from the figure that the increasing damping torque leads to the increase of the contact pressure. With the increase of the contact pressure, the texture of the marks on the initial grinding surface is continuously changed, and the distance between the marks is gradually widened. When the traces of the processed ravines are processed, the surface morphology distribution is more smooth, and there are no obvious crack defects, and the texture is fine.

The surface roughness ( $\mathrm{Ra}$ and $\mathrm{Rq}$ ) images of the untreated and treated samples are shown in Figure 17. It can be noticed that there are obvious wear scars on the surface of the untreated sample, and the outline shows large peaks and valleys, resulting in relatively high $\mathrm{Ra}$ and $\mathrm{Rq}$, which are 0.377 and 0.467 , respectively. For the $30 \mathrm{Nm}$ sample, the grinding marks are basically removed, but the peak-to-valley surface is still larger than the distance between the grinding marks, which causes $\mathrm{Ra}$ and $\mathrm{Rq}$ to decrease by 0.114 and 0.132 , respectively. When the torque is $60 \mathrm{Nm}$, the surface profile is all small peaks and valleys, with large peaks and valleys interspersed in the middle, and the roughness is reduced to Ra of 0.111 and $\mathrm{Rq}$ of 0.134 . Compared with $30 \mathrm{Nm}$ and $60 \mathrm{Nm}$, the grinding marks of $80 \mathrm{Nm}$ specimens are almost removed, and the peaks and valleys are no longer visible on the surface contour lines, and the roughness is reduced to Ra0.09 and Rq0.1; after treatment, the surface roughness $\mathrm{Ra}$ is increased respectively $30 \%, 70 \%, 76 \%$. After the treatment, the surface appears smooth as a whole, the roughness profile peaks fill the valleys, and the peaks and valleys are changed. The defect of stress concentration after grinding is removed, and the fatigue strength of the material can be improved. 


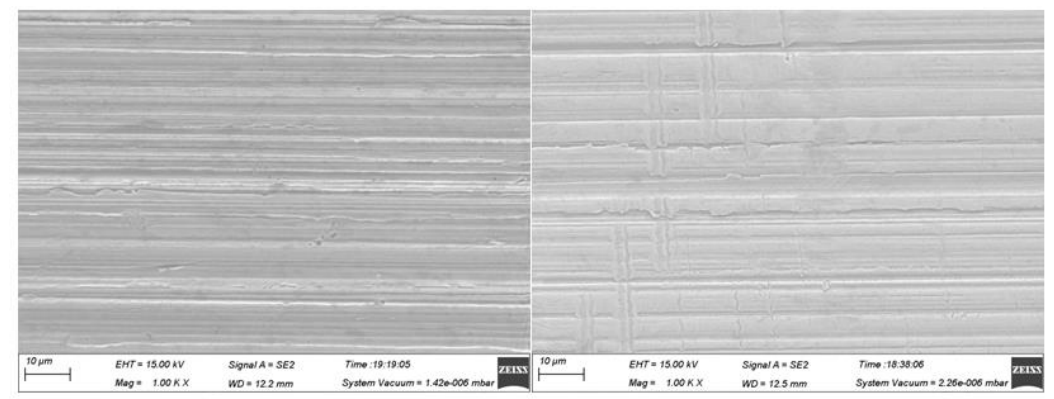

(a) Initial surface

(b) $30 \mathrm{Nm}$

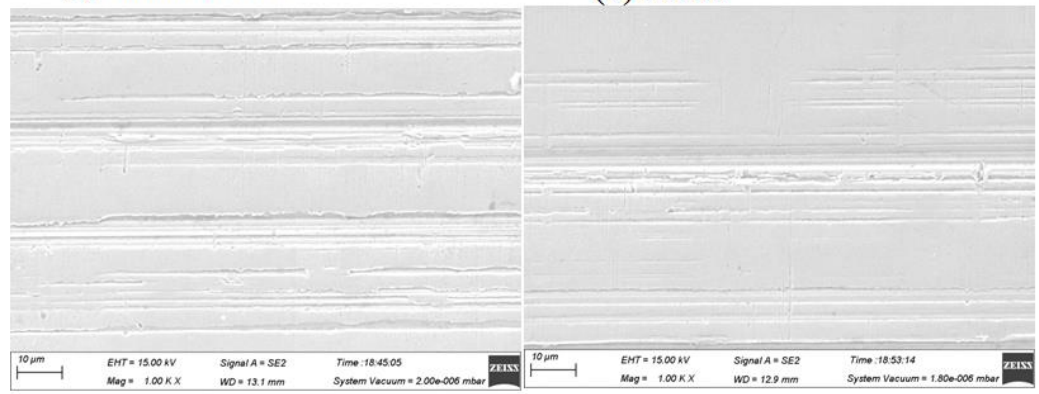

(c) $60 \mathrm{Nm}$

(d) $90 \mathrm{Nm}$

Figure 16. SEM of the surface at the pitch circle

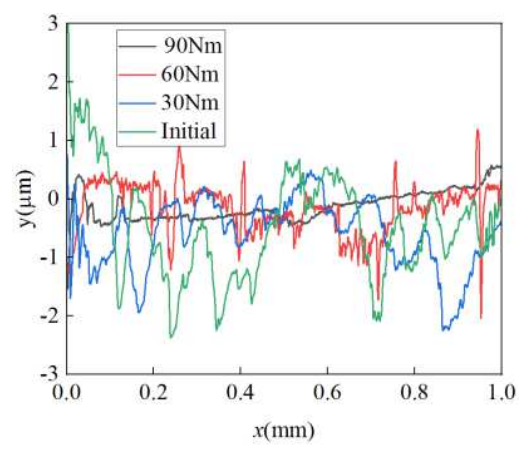

(a) Roughness profile

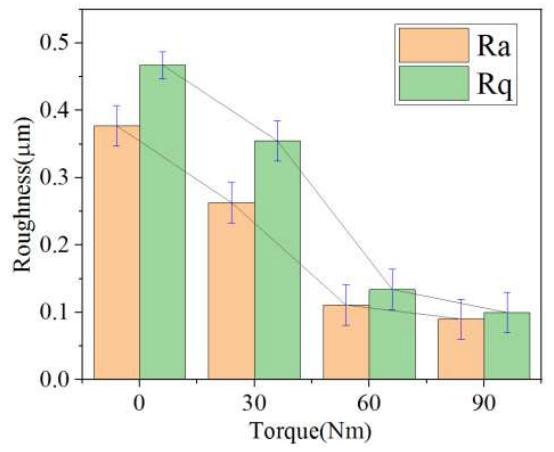

(b) $\mathrm{Ra}$ and $\mathrm{Rq}$ diagrams

Figure 17. Roughness comparison

To sum up, ultrasonic rolling can improve the roughness and surface appearance of the gear tooth, the main reasons are as follows: the displacement of the contact point strengthened by this mode is the longitudinal space sine curve, and the displacement of different nodes interweave with each other, which makes the peak-valley width of the surface become wider and the residual material height of the surface reduced after rolling and sliding repeatedly, this process reduces surface roughness and improves surface quality.

\section{Conclusions}

(1) Combined with ultrasonic rolling strengthening technology and gear meshing principle, the rolling enhanced acoustic system for the gear was proposed to realize the strengthening gear surface.

(2) A multi-segment double-node compound horn system were designed and manufactured to meet the requirements of REAS. The transducer was designed by half wavelength, and the horn was designed by one wavelength. The frequency equation of the double-node horn was established by the one-dimensional wave vibration theory, the correctness of which is proved by experiment and simulation.

(3) By modal analysis and harmonic response analysis, it was concluded that the influence of mass increase on the ultrasonic rolling system depended on the way of mass increase. The constant diameter gear had little effect on the system frequency with the change in thickness (mass). With the increase in the diameter (mass) with equal thickness, the frequency 
of the URS became smaller, and the position of the double nodes was close to the gear end. The span difference in the double nodes varied in a small range. The amplitudes of different gear resonant systems (GRS)were different. The frequency of GRS decreased with the increase in diameter, and the amplitude of the horn (with no gear) was the largest. The amplitude was reduced after the gear was installed.

(4) The self-built URES was used to strengthen the gears with the diameter of $60 \mathrm{~mm}$. Some plastic deformation occurred in the tooth surface with ultrasonic rolling, and the surface texture changed. At the same time, the surface roughness reduced, and the surface brightness, tooth surface hardness, and residual stress increased. These findings indicated that the gear tooth surface strengthening treatment provided a new way of thinking.

\section{Declarations}

Funding This work was financially supported by the National Natural Science Foundation of China (Nos. U1604255 and 51475148).

Competing interests The authors declare that no potential conflicts of interest with respect to the research, authorship, and/or publication of this article.

Availability of data and material All data generated or analyzed during this study are included in the present article. Code availability Not applicable.

Ethical approval The article follows the guidelines of the Committee on Publication Ethics (COPE) and involves no studies on human or animal subjects.

Consent to participate Not applicable.

Consent to publish Not applicable.

Authors' contribution Yan Jiang conceived the analysis and wrote the manuscript. Bo Zhao provided supervisions on experimentation and manuscript preparation. The authors discussed each reference paper together and contributed useful ideas for this manuscript.

\section{References}

1. Tonshoff, H. K. and Marzenel, C (2000) Effect of gear honing on flank characteristics and pitting life. Production Engineering 7(1): 5-8.

2. Ariura, Y, Ueno, T, and Nakanishi (1983) Aninvestigation of surface failure of surface-hardened gears by scanning electron microscopy observations. Wear 87(3): 305-316.

3. Sjberg S, Bjrklund S, Olofsson U (2011) The influence of manufacturing method on the running-in of gears. P I Mech Eng J-J Eng 225(10): 999-1012.

4. Andersson, S (1977) Initial Wear of Gears. Tribol Int 10(4): 206-210.

5. Ismail R, Tauviqirrahman M, Jamari K, et al (2011) Topographical change of engineering surface due to running-in of rolling contacts. InTech.

6. Oila A, Bull SJ (2005) Assessment of the factors influencing micropitting in rolling/sliding contacts. Wear 258(10): 1510-1524.

7. Li S, Kahraman A (2013) Micro-pitting fatigue lives of lubricated point contacts: Experiments and model validation. Int J Fatigue 48(3): 9-18.

8. Ariura Y, Ueno T, Nakanishi T (1983) An investigation of surface failure of surface-hardened gears by scanning electron microscopy observations. Wear 87(3): 305-316.

9. Bergseth E, SjBerg S, BjRklund S (2012) Influence of real surface topography on the contact area ratio in differently manufactured spur gears. International Tribology 56: 72-80.

10. Akbarzadeh S, Khonsari M M (2013) On the optimization of running-in operating conditions in applications involving EHL line contact. Wear 303(1-2): 130-137.

11. Sjberg S, Sosa M, Andersson M, et al (2016) Analysis of efficiency of spur ground gears and the influence of 
running-in. Tribol Int 93: 172-181.

12. Andersson M, Sosa M, Olofsson U (2016) The effect of running-in on the efficiency of superfinished gears. Tribol Int 80: 71-77.

13. Wei BY, Deng XZ, Fang ZD (2007) Study on ultrasonic-assisted lapping of gears. Int J Mach Tool Manu 47(12-13): 2051-2056.

14. Pathak S, Jain NK, Palani IA (2016) Investigations on surface quality, surface integrity and specific energy consumption in finishing of straight bevel gears by PECH process. Int J Adv Manuf Tech 85(9-12): 2207-2222.

15. Liu H, Zheng J, Guo Y, et al (2020) Residual stresses in high-speed two-dimensional ultrasonic rolling 7050 aluminum alloy with thermal-mechanical coupling. Int J Mech Sci 186: 105824.

16. Zheng J, Liu Ren Y, et al (2020) Effect of two-dimensional ultrasonic rolling on grain size and micro-hardness of 7075 aluminum alloy. Int J Adv Manuf Tech 106(9-12): 1-8.

17. Wang T, Wang DP, Liu G, Gong BM, Song NX (2008) Investigations on the nanocrystallization of 40Cr using ultrasonic surface rolling processing. Appl Surf Sci 255(5): 1824-1829.

18. Li G, Qu SG, Pan YX, Li XQ (2016) Effects of the different frequencies and loads of ultrasonic surface rolling on surface mechanical properties and fretting wear resistance of HIP Ti-6Al-4V alloy. Appl Surf Sci 389: 324-334.

19. Cheng ML, Zhang DY, Chen HW, Qin W, Li JS (2016) Surface nanocrystallization and its effect on fatigue performance of high-strength materials treated by ultrasonic rolling process. The Int J Adv Manuf Tech 83(1-4): 123-131.

20. Jiao F, Lan S L, Zhao B, WANG Y (2020) Theoretical calculation and experiment of the surface residual stress in the plane ultrasonic rolling. J Manuf Process 50: 573-580.

21. Dang JQ, An QL, Lian GH, Zuo ZY, Li YG, Wang HW, Chen M (2021) Surface modification and its effect on the tensile and fatigue properties of 300M steel subjected to ultrasonic surface rolling process. Surf Coat Tech 422:127566.

22. Sosa MB, Jrklund S, Sellgren U, et al (2015) In situ surface characterization of running-in of involute gears. Wear 340: 41-46.

23. Mallipeddi D, Norell M, Sosa M, et al (2019) The effect of manufacturing method and running-in load on the surface integrity of efficiency tested ground, honed and superfinished gears. Tribol Int 131: 277-287.

24. Rai P,Jain N K, Pathak S (2019) Experimental investigations on surface finish and microgeometry of helical gear in pulsed-electrochemical honing process. P I Mech Eng C-J Mec Science 233(10): 3364-3375.

25. Wu YR, Tran VT (2016) Transmission and load analysis for a crowned helical gear pair with twist-free tooth flanks generated by an external gear honing machine. Mech Mach Theory 98: 36-47.

26. Zhao B, Chang BQ, Wang XB, et al (2019) System design and experimental research on ultrasonic assisted elliptical vibration grinding of Nano-ZrO2 ceramics. Ceram Int 45(18): 24865-24877.

27. Deng XZ, Yang JJ, Wei BY, Fang DZ (2007) Dynamic lapping force analysis of spiral bevel gear lapping system with ultrasonic excitation. China Mechanical Engineering (19): 95-97.(in Chinese)

28. Ilaiyavel S, Venkatesan A (2012) Experimental investigation of wear characteristics on manganese phosphate coated AISI D2 steel. Int J Precis Eng Man 13(4): 581-586.

29. Han S, Lin JH, Wang GH, et al (2003) The effect of preferred orientation on the mechanical properties of chromium nitride coatings deposited on SKD11 by unbalanced magnetron sputtering. Mater Lett 57(5/6): 1202-1209.

30. Tonshoff H, Marzenell C (2000) Effects of Gear Honing on Flank Characteristics and Pitting Life. 2000. 